\title{
Urdimento
}

Revista de Estudos em Artes Cênicas

E-ISSN: 2358.6958

\section{Trabalho teatral latino-americano: pedagogias dissonantes em dois tempos históricos}

Rafael Litvin Villas Bôas

Douglas Estevam

\section{Para citar este artigo:}

VILLAS BÔAS, Rafael Litvin; ESTEVAM, Douglas. Trabalho teatral latino-americano: pedagogias dissonantes em dois tempos históricos. Urdimento, Florianópolis, v. 2, n. 38, ago./set. 2020.

DOI: http:/dx.doi.org/10.5965/14145731023820200039

Este artigo passou pelo Plagiarism Detection Software | iThenticate 
Trabalho teatral latino-americano: pedagogias dissonantes em dois tempos históricos

Rafael Litvin Villas Bôas ${ }^{1}$

Douglas Estevam²

\begin{abstract}
Resumo
O artigo tem como objetivo sistematizar quais os eixos estruturantes da pedagogia teatral presente em alguns dos grupos que integraram Frente de Trabalhadores da Cultura Nuestra America, por meio de textos de dramaturgos e diretores e da experiência dos grupos. O intuito é identificar as características comuns nas formas organizativas e nos processos de resistência. Para isso a pesquisa recupera a história da articulação dos trabalhadores da Cultura nos anos 1960 e 1970 na América Latina, analisa o processo de composição da rede que surge inspirada nos debates, ações e propostas estéticas daquele período, a Rede de Teatro e Vídeo Político- Popular de Nuestra América.
\end{abstract}

Palavras-chave: Trabalho teatral. Pedagogias do teatro. Organização em rede. Criação colaborativa.

\title{
Latin American theatrical work: dissonant pedagogies un two historical times
}

\begin{abstract}
The article aims to systematize the structuring axes of theatrical pedagogy present in some of the groups that were part of the Nuestra America Cultural Workers Front, through texts by playwrights and directors and the experience of the groups. The aim is to identify common characteristics in organizational forms and resistance processes. To this end, the research recovers the history of the articulation of the workers of Culture in the 1960s and 1970s in Latin America. It analyzes the process of composition of the network that emerges inspired by the debates, actions and aesthetic proposals of that period, the Network of Political Theater Popular from Nuestra América.
\end{abstract}

Keywords: Theatrical work. Theater pedagogies. Network organization. Collaborative creation.

\footnotetext{
Prof. Dr. Programa de Pós-Graduação em Artes Cênicas e do Mestrado Profissional em Artes da Universidade de Brasília (UnB), e do Mestrado em Desenvolvimento Territorial da América Latina e Caribe e Escola Nacional Florestan Fernandes. rafaellvboas@gmail.com

${ }^{2}$ Historiador pela Universidade Federal da Fronteira Sul. Coordenador da Brigada Nacional de Teatro do MST. douggestevam@gmail.com
} 
Obra teatral latino americana: pedagogías disonantes em dos tempos históricos

\section{Resumen}

El artículo tiene como objetivo sistematizar los ejes estructurantes de la pedagogía teatral presente en algunos de los grupos que formaron parte del Frente de Trabajadores de la Cultura de Nuestra América, a través de textos de dramaturgos y directores y la experiencia de los grupos. El objetivo es identificar características comunes en formas organizacionales y procesos de resistencia. Para ello, la investigación recupera la historia de la articulación de los trabajadores de la cultura en los años sesenta y setenta en América Latina, analiza el proceso de composición de la red que surge inspirada en los debates, acciones y propuestas estéticas de ese período, la Red de Teatro y Video Político y Popular Nuestra América.

Palabras-clave: Trabajo teatral. Pedagogías teatrales. Organización de red. Creación colaborativa. 
Nas décadas de 1950 a 1970 muitos países da América Latina vivenciaram experiências de engajamento artístico sintonizadas com processos de lutas sociais populares de setores de trabalhadores do campo e da cidade. O artigo tem como objetivo analisar as características comuns dos coletivos daquele período, por meio das posições de alguns dos principais diretores, dramaturgos e teóricos do período, e comparar a dinâmica do trabalho teatral desenvolvido naquelas décadas com as articulações e modos de produção de coletivos e movimentos que trabalham com teatro como meio de intervenção crítica sobre o real, e como método de formação e organização social.

Na introdução ao livro Teatro Popular y cambio social en America Latina: panorama de uma experiência (1979) a organizadora Sonia Gutiérrez informa que, no modo de fazer do teatro popular latinoamericano, se distinguiam basicamente duas maneiras de trabalhar: a correspondente à produção dos grupos de favelas, fábricas e comunidades camponesas, em alguns casos com assessoria de promotores teatrais externos ou definidos entre os integrantes dos grupos; e a outra maneira que, ainda que se destine à comunidades pobres, a obra conta com maior aplicação de técnicas teatrais, demandando cenários mínimos e, sobretudo, os grupos de criação são externos às comunidades.

Gutiérrez está de acordo com Augusto Boal quando afirma: "Para Boal se hace necessário alcanzar a todos los sectores sociales a los cuales la información real les es ocultada por los médios oficiales de comunicación” (Gutiérrez, 1979, p. 05). O primeiro passo, nesse sentido, segundo a autora, seria o conhecimento do significado básico da mensagem teatral: a realidade latinoamericana vivenciada pela maioria da população, com desemprego, fome e miséria crescente.

Para plantearse este último como meta es necessário tener presente el fator decisivo: la lucha. Y es justamente aquí donde se ubica el trabajo teatral latinoamericano como un trabajo artístico, bello en tanto motiva esta lucha transformadora de la realidad: Lucha llevada a cabo diariamente por la clase explotada. (Gutiérrez, 1979, p. 06).

A autora assinala ainda que a América Latina é marcada por larga tradição de convergência entre a prática teatral e a prática política, e no marco da luta política, 
o lugar da prática teatral é o da batalha ideológica. Compreendida essa luta como o ato de desvelamento da ideologia dominante e de suas estruturas opressoras, tendo como objetivo a perspectiva de transformação social. Todavia, como o sujeito chave dessa transformação é constituído pela classe oprimida, a ideologia dessa classe é um elemento essencial. "Em resumen, la obra teatral crea um mensaje comprometido politicamente com la lucha popular cuando incorpora artisticamente elementos de la ideologia dominante y de la ideologia revolucionaria." (Gutiérrez, 1979, p. 06).

Por esse motivo muitos grupos que desenvolveram práticas colaborativas estabeleceram contatos com organizações de intelectuais, centros de pesquisa, para se apropriar de conhecimentos das áreas de economia, história, ciência política, dentre outros, que passaram a ser necessários na medida em que os temas eleitos para construção das peças eram decididos a partir de demandas da luta popular. Por exemplo, quando Vianinha ${ }^{3}$ decide construir uma peça para explicar aos trabalhadores o que é a mais-valia, ele busca apoio de sociólogos como Carlos Estevam Martins, e dessa forma foi constituindo uma equipe multidisciplinar que coordenou as frentes de produção artística dos Centros Populares de Cultura da União Nacional dos Estudantes, no Brasil. A peça A mais valia vai acabar, seu Edgar é emblemática desse projeto coletivo de pesquisa e intervenção estética e política (Costa, 1996).

Nesse aspecto, o trabalho de alguns coletivos se tornaram referência pela consolidação de métodos que buscaram conjugar rigor teórico e metodológico na forma de interpretação da realidade, e apuro e eficácia estética na transfiguração em forma artística do material pesquisado. Foi o caso do coletivo cubano Teatro Escambray, formado por integrantes de elencos teatrais profissionais da capital de Cuba, Havana, que decidiram voluntariamente migrar para a Serra Escambray, movidos pelo intento de colaborar com o processo revolucionário, e pela insatisfação com o meio teatral tradicional da capital. Na serra enfrentaram um

3 Oduvaldo Vianna Filho, dramaturgo e ator, atuou no Teatro Paulista do Estudante (TPE), no Teatro de Arena e fundou o Centro Popular de Cultura (CPC). Autor de peças premiadas como Quatro quadras de Terra (Prêmio Casa das Américas, em Cuba, em 1962), e Os Azeredo mais os Benevides (Prêmio do Serviço Nacional de Teatro, em 1963). Escreveu ainda A mais valia vai acabar, seu Edgar (1961), Rasga Coração (1974), dentre outras peças e séries televisivas. 
foco de contrarrevolucionários que tinha por intuito derrotar a Revolução Cubana, e se colocaram a disposição do processo de formação e organização social dos camponeses, construindo repertório de peças concatenado com as demandas identificadas pela célula local do Partido Comunista Cubano. Vencido o foco reacionário, se colocava o desafio de promover importantes obras de desenvolvimento na zona que tinha sido particularmente abandonada, em tempos da republica neocolonial. De acordo com Graziella Pogolotti, a respeito do método de trabalho desse coletivo cubano:

Los primeros espectáculos fueron sobre todo el instrumento para la puesta en contacto con los habitantes de la zona. Más importante fue comprender que si la convivencia era necesaria para el estudio de la nueva realidad, éste requería, asimismo, una sistematización. Aunque se trataba de artistas y no de profesionales de la investigación, procedieron a elaborar, con la ayuda de compañeros de formación universitaria, un primer esquema de guía, destinado a llevar a cabo entrevistas abiertas. Se recogía así un rico material, que abarcaba desde la tenencia histórica de la tierra, hasta las características del actual modo de vida. (Pogolotti apud Leal, 1978, p. 16).

Analisando os modos de produção dos coletivos Gutiérrez propõe a seguinte interpretação:

Así que distinguir el Teatro Popular unicamente por el grupo que lo produce (obreiros, campesinos, marginados) o por la problemática ligada a la realidad inmediata de la clase popular, no es suficiente. Requiere de una dimensión mayor: la ubicación de las problemáticas teatrales en una perspectiva de análisis critico de la sociedad capitalista y su contribucion al proyecto político de la clase popular. (Pogolotti apud Leal, 1978, p. 08).

\section{A origem da Frente de Trabalhadores da Cultura Nuestra América}

A produção teatral radical e crítica que se conjuga a uma nova forma organizativa a partir dos festivais iniciados em 1968 é resultado do processo histórico que tem seu marco inicial com o triunfo da Revolução Cubana em 1959. Um novo impulso dado à integração continental surgiu em janeiro de 1966, quando 
em um encontro com delegados de 82 países, a maior parte da América Latina, Ásia e África, é criada a Tricontinental com o objetivo de lutar pela liberação e a soberania nacional e o direito a autodeterminação dos povos. Foi na revista da Tricontinental que apareceu o texto de Che Guevara com a célebre consigna de criar dois, três, muitos Vietnãs. (Estevam, 2019).

Augusto Boal chega em Cuba no momento em que a Ilha vivia sob a influência continental da chamada "meditação de 68". Naquele ano de 1968 foram realizados o Primeiro Festival Latino-americano de Teatro de Manizales, o Congresso Cultural de La Habana (com 450 artistas, escritores, cientistas e educadores de 70 países da América Latina, África, Ásia e Europa) e o Primeiro Festival Internacional de Teatro de La Habana. Com os festivais a integração cultural latino-americana ganhava corpo com iniciativas concretas de aproximação entre os grupos de teatro universitário e independentes.

Foi criado um Comitê Permanente dos Festivais Internacionais, do qual a revista cubana Conjunto, da Casa de las Américas, se converteria em uma espécie de órgão central. A chamada “meditação de 68" teve inicio a partir da realização do I Seminário de Teatro de Cuba, organizado pelos trabalhadores de teatro no final de 1967. O Manifesto do seminário dava o tom da concepção que estaria em disputa nos festivais que então se iniciavam. No documento, se afirma que:

Arte, Pueblo y Revolución son tres valores que no sólo pueden, sino que deben compenetrarse mutuamente. Desde luego, eso requiere que los trabajadores del teatro sean al mismo tiempo pueblo, artistas y revolucionarios. (Pianca, 1990, p. 151).

Na “Declaracion de principios del primer seminário de teatro (1968)" afirmavase: "Nuestra actitud debe ser consecuente y profunda. Nuestro principio debe ser, sobre todo, hacer teatro en todos los rincones del país, haya o non haya teatro" (Pianca, 1990, p. 344). A problemática da relação com o público e da utilidade da linguagem teatral está presente:

No es a través del populismo como um teatro se convierte em popular. [...]. Ni paternalismo ante los públicos massivos que por 
primera vez em su historia pueden acudir a um teatrão, ni concessiones facilistas. La creación de um teatro popular esta ligado a la formación de ese nuevo público. La popularidad de un teatro sólo es posible na medida en que arraiga em las massas y las educa.

El teatro no es una ideología, pero sí instrumento de una ideología. El teatro es hoy parte de la realidad misma, es un centro de gravedad, está dentro de la sociedad. El teatro es ahora una forma dialética de comunicación, que trata de establecer la responsabilidad histórica del individuo dentro de la sociedad. [...].

La máxima expresión de la utilidad de ese instrumento se da hoy en Viet Nan, donde, bajo las bombas, se hace teatro. (Pianca, 1990, p. 345).

Os esforços de popularização da arte em Cuba ocorreram em várias frentes, embora essa linha só viesse a se consolidar efetivamente em 1969 (Pianca, 1990, p. 68). Em 1960, em momentos de grandes lutas e combates internos em Cuba, e também de crescimento do apoio internacional, se formou a primeira Brigada de Teatro, levando apresentações aos lugares mais distantes, como por exemplo na Sierra Maestra e na zona de Escambray, esta última conhecida como um centro da contrarrevolução. Em 1961 as jornadas de alfabetização mobilizaram mais de 100 mil pessoas com o objetivo de alfabetizar 700 mil pessoas. Foram multiplicadas novas brigadas que atuaram em várias partes de Cuba. Estima-se que em 1962 houve cerca de 360 apresentações.

Essa não seria a única experiência articulando alfabetização e teatro. Anos mais tarde, Boal participaria de outra iniciativa desenvolvida no Peru, com o projeto Alfabetização Integral (ALFIN) e na revolução Sandinista teríamos novamente experiências semelhantes. Os objetivos das Brigadas eram criar uma nova tradição teatral, em diálogo com o repertório das tradições populares, levar o teatro aos lugares mais distantes, criar um novo teatro nacional, formar novos atores, autores e diretores. Entre as obras apresentadas pelas brigadas estava Eles não usam Black-Tie, de Guarnieri, peça central que marcou a transformação definitiva do Teatro de Arena e uma nova fase na produção teatral brasileira.

Augusto Boal procurou resistir ao ciclo autoritário que se iniciava na América Latina, na década de 1960, recuperando e revitalizando métodos de agitação e propaganda desenvolvidos na União das Repúblicas Socialistas Soviéticas (URSS) 
e na Alemanha, como o Teatro Jornal4 (Lima, 2014) e o Teatro Invisível (Villas Bôas, 2019). E, foi durante o exílio que foi convidado a participar do projeto ALFIN, desenvolvido no Peru, durante o único regime militar do período que operou um processo de modernização conservadora de caráter ambíguo, em que um dos polos consistiu em contemplar parte da pauta popular, como a realização da reforma agrária, sem, contudo, permitir o protagonismo das populações indígenas andinas, camponeses e operários, que protestavam por mudanças radicais no país. Ao invés de sufocar e reprimir as classes populares, o governo do General Lopez Alvarado decidiu investir na educação.

O sistema ALFIN foi baseado nas ideias da Pedagogia do Oprimido, de Paulo Freire. Em dois anos e meio foram alfabetizados 250 mil camponeses e operários peruanos. Os objetivos da fase inicial de alfabetização eram três, sendo um deles o aprendizado e manejo dos meios de comunicação social, tradicionais (rádio, televisão, jornal) e não tradicionais (bonecos, teatro popular, gravação de áudio, fotomontagem, serigrafia, imprensa popular, etc.), com o propósito de serem utilizados como instrumento de analise crítica da realidade social dos alfabetizandos (desmontagem ideológica) e como meios de expressão de suas próprias mensagens e discursos.

Na edição do festival na Colômbia foi realizado um novo encontro da Frente Latino-americana de Trabalhadores da Cultura e formulado um segundo comunicado com um chamado e os objetivos da Frente (Pianca 1990, p. 351). Em assembleia reunida no encontro foi aprovada um junta diretiva da Frente que funcionaria até o próximo encontro. Entre os eleitos pela assembleia, Augusto Boal aparece como o representante do Brasil. São estabelecidos objetivos imediatos da Frente, avançando na organização da mesma a partir das organizações teatrais existentes nos países e apoiando a criação de outras organizações culturais semelhantes em outros países. Fica estabelecido que (Pianca, 1990, p. 352): a

4 De acordo com Maria Silvia Betti é uma forma "que propunha a teatralização de notícia de jornal - nomeada “jornais vivos" (living newspapers) pelos estadunidenses e "Teatro Jornal” pelos brasileiros -, respondeu, em ambos os casos, à necessidade concreta e imediata de denunciar e discutir aspectos e implicações da conjuntura política e econômica não acessíveis ap público da classe trabalhadora. Tanto em um como em outro contexto, seu horizonte foi o da luta contra a supressão dos direitos e a exploração, e seu campo artístico foi o da agitação e propaganda, inscrevendo-a na história cultural da esquerda." (Betti apud Lima, 2014, p. 07). 
Frente terá como base fundamental de sua atividade a comunicação entre os diferentes movimentos e agrupações teatrais e culturais com o objetivo de romper as barreiras tradicionalmente imposta entre os países do continente. Essa comunicação se efetuaria através de boletins informativos dos distintos países, organização de cursos, encontros, turnês, seminários (Ibidem, p. 352). Fica clara a dimensão programática que essas atividades pedagógicas e de publicações assumiam no processo de articulação continental. Um dos objetivos era o estabelecimento, por meio da Frente, de uma política em relação aos distintos Festivais Latino-americanos que começam a se desenvolver em vários países, um ponto de extrema importância para a manutenção de uma orientação política dos encontros. O documento ainda denunciava o acirramento das lutas no Chile e aponta a solidariedade com os trabalhadores, camponeses, e governo revolucionário e também apoio ao Uruguai, que vinha de sofrer um golpe cuja repressão havia impedido que o grupo Galpón participasse do encontro. Seu diretor, Atauhalpa del Cioppo, também foi nomeado à diretiva da Frente.

Durante esse Festival os grupos também se reuniram num importante esforço de síntese do percurso recente e para buscar uma aproximação ao conceito de teatro popular, elencando pontos de aproximação entre as práticas, métodos e formas de trabalho. Foi organizada uma comissão de redação que sistematizou as reflexões coletivas no "Documento sobre o teatro popular" (Pianca, 1990, p. 335), de extremo valor por apontar a posição conjunta dos grupos. O primeiro ponto da sistematização aborda o teatro popular na luta de classes. Segundo a avaliação dos grupos, o teatro estava deixando de ser um produto estético, fechado em si mesmo, para converter-se em um instrumento de conscientização, agitação e organização da luta contra o imperialismo.

El teatro deja de ser un producto estético, encerrado en sí mismo y se transforma en una herramienta de trabajo al servicio de las masas populares en la lucha por la liberación total.

Para cumplir eficazmente esta función, se plantea la necesidad de ligarse a organizaciones políticas (partidos), u organismos de masas (sindicatos, ligas campesinas, centros vecinales, etc.) que capitalicen el trabajo teatral. 
Aprovechar también actos, movilizaciones y concentraciones del pueblo (huelgas, tomas de tierras, etc.) para participar e impulsar la lucha de clases. (Pianca, 1990, p. 336).

Assim como a reflexão feita em Cuba em 1968, os grupos reunidos na Colômbia concebiam os trabalhadores do teatro como ativistas ou militantes revolucionários. O teatro popular é definido como aquele que se insere nos processos revolucionários e participa da luta de classes, contribuindo assim para a transformação da sociedade. Sem idealizar ou ocultar possíveis diferenças existentes entre os trabalhadores de teatro e o povo, a superação da dicotomia seria dada através da participação conjunta na luta de classes, em estreita e contínua relação com as massas, superando atitudes dogmáticas, esquemáticas ou paternalistas.

A linguagem do teatro popular também é analisada, defendendo que para trabalhar com um conteúdo revolucionário seriam necessárias formas novas, revolucionárias, mas sem abstrações, especificando que: "Es entonces cada circunstancia concreta la que va determinando y conformando nuestro linguaje." (Pianca, 1990, p. 337).

Entre as novas atitudes e propostas formuladas pelo coletivo, aparecem o trabalho com as formas culturais populares, incluindo as culturas autóctones e indígenas. De acordo com o "Documento sobre Teatro Popular" a autocrítica deve ser uma atitude constante para o ajuste do trabalho à realidade (Pianca, 1990, p. 339). Além disso, é apontada como uma área de suma importância para o teatro popular a criação de grupos formados por operários e populares que deem, mediante suas próprias formas, conta de seus próprios problemas. Nessa questão, seria preponderante, segundo o documento, o papel do trabalhador de teatro como incentivador da tarefa teatral mesmo fora de sua função como integrante de um grupo (Pianca, 1990, p. 339). O documento articula os elementos centrais que iriam nortear a ação dos grupos na construção de uma articulação continental e estabeleceria os parâmetros para o projeto continental que se estruturava. As referências dessas formulações pautaram as concepções dos festivais, assim como o processo pedagógico e de intercâmbio que se realizavam 
em torno deles, com os debates, oficinas, cursos e trocas de experiências.

\section{A procura da particularidade latino-americana como forma de expressão contra-colonizadora}

A década de 1960 foi marcada pela ascensão de teorias que expressavam formas originais de interpretação das contradições entre o centro e a periferia do sistema mundial. A Teoria da Dependência (Cardoso, 1981; Marini; 2000) compreendia que não seria possível transpor o estágio de subdesenvolvimento que caracterizava os países colonizados do hemisfério sul, mas apenas em alguns casos desenvolver o subdesenvolvimento. A única possibilidade seria a ruptura por meio de processos revolucionários, como o ocorrido em Cuba, em 1959, que contagiou a luta popular na maioria dos países latino-americanos, por mostrar que seria possível lutar contra a dinâmica imperialista e conquistar a autodeterminação, alfabetizar a população, fazer a reforma agrária, estabelecer regras justas e de interesse nacional no sistema tributário, regular o lucro das empresas multinacionais, e investir na indústria nacional em busca da soberania nacional.

Nas artes cênicas essa concepção pode ser encontrada no depoimento de muitos dramaturgos e diretores, como Santiago Garcia, do La Candelária (Chile), que responde ao ser indagado sobre o que pensa do teatro latinoamericano:

A América está à margem da Europa, dos Estados Unidos e mesmo da Ásia. Somos marginais e, por isso mesmo, estamos estabelecendo essa proposta de laboratórios, de oficinas, de estudos para encontrar novas possibilidades para o teatro. Sem querer ser chauvinista nem provinciano eu poderia dizer que os olhos da Europa e mesmo dos Estados Unidos estão fixados sobre as nossas possibilidades de teatro na América Latina. Eles estão muito interessados em ver o que estamos fazendo. Para os Europeus, o teatro está em crise criativa. Faz muito tempo que não existem autores.

[...]. Como latino-americanos temos que aprofundar na nossa particularidade, na nossa tipicidade, onde podemos encontrar as raízes da nossa identidade, que, particularizando-se, podem tornarse cada vez mais universais. (Garcia, 1988, p. 127). 
A procura da expressão singular da experiência latino-americana a partir da expressão estética da realidade da população dos países, pelo ponto de vista dos explorados, dos vendedores da força de trabalho aos donos dos meios de produção, configurou a procura por uma identidade nacional-popular em muitos países. Todavia, o "nacional” não se configurava como categoria excludente e chauvinista, pelo contrário, se expandia para a construção da consciência latinoamericana. Isso foi resguardado por meio de ações concretas como o compartilhamento das peças construídas pelos grupos, que foram montadas por elencos de diversos países, como foi o caso do grupo uruguaio El Galpón, que montou "Eles não usam black-tie" de Guarnieri, ator e um dos dramaturgos do Teatro de Arena (SP). Essa crescente consciência dos artistas e intelectuais refutava as formas de pasteurização e de construção de estereótipos operadas pela Indústria Cultural. Conforme Garcia (1988, p. 129):

Enxergar o latino-americano como uma unidade, como uma arte de exportação, é um rumo ao qual nos querem levar as influências colonialistas. Tenta-se ver este leque de possibilidades que constituímos e reduzi-lo a um conjunto de códigos muito elementares através dos quais nos possam ler os europeus. Temos que rejeitar isto, decididamente, e cada país deve encontrar sua expressão artística, sociológica ou política. Cada país deve encontrar seus próprios, autênticos e sinceros meios de expressão.

O tema da luta anticolonial e a busca por formas específicas de expressão latino-americana também foi tematizado por Augusto Boal (1973) no texto "Uma revolução copernicana ao revés", inserido no livro Técnicas Latino-americanas de Teatro Popular. Baseando-se na multiplicidade de formas que constituem o processo de produção do teatro latino-americano, Boal articula os aspectos da revolução copernicana em curso e que configuram um "projeto continental"5. O centro dessa revolução é a luta contra o colonialismo cultural, contra o mimetismo, contra os que querem "ser tão bons quanto os europeus" (Boal, 2014, p. 120). A imagem refere-se a uma inversão dos polos das relações culturais do

${ }^{5}$ A historiadora argentina Marina Pianca fala de um "projeto continental", preocupado com a criação de uma "nova cultura", em um novo contexto histórico e uma nova arte (Pianca, 1990, p. 26). 
continente. Se, até então, havíamos sido satélites da arte metropolitana, agora seríamos o centro de nosso universo artístico.

Em suas análises e sistematizações, Boal opera com categorias similares, em consonância com os aspectos da produção teatral e da reflexão teórica daquele momento histórico. A preocupação com a construção de poéticas sócio-históricas está presente no conjunto de suas obras, lembrando que o título inicial do livro Teatro do Oprimido seria Poéticas Políticas, que só veio a se tornar subtítulo por orientação do editor brasileiro. A relação problematizada, contraditória e dialógica da relação com o povo, a dialética das diferenciações internas das categorias de popular, é abordada na primeira parte de Técnicas, que retoma um texto escrito ainda no Brasil em 1970, intitulado Categorias do teatro popular. Os trabalhos desenvolvidos no Teatro de Arena, a busca de uma dramaturgia nacional ampliada pela realização dos seminários de dramaturgia, a investigação laboratorial no campo interpretativo, aliavam uma dimensão pedagógica e processual do trabalho, geradora de movimentos organizativos e coletivos, como os Centros de Cultura Popular - CPC. Esses são alguns dos momentos formativos do percurso de Boal antes de seu exílio e que faziam parte de uma dinâmica comum, com suas particularidades locais, a vários grupos latino-americanos.

Enrique Buenaventura, ao lado de Augusto Boal uma das referências na construção da articulação, também empreendeu o esforço de sistematização das experiências de teatro popular em curso naquelas décadas, elencando os elementos constituintes desse teatro. Segundo ele, a experiência teria um caráter de movimento teatral. A problemática da "dramaturgia" seria um ponto central, com a elaboração de uma temática e forma nacional (incluída a fase de nacionalização dos clássicos). Buscava-se a ruptura com certa tradição, prática e teórica, assumindo como foco o processo de produção artística; a construção de uma nova relação com o público, em condições e espaços novos, que influenciariam na produção e na própria dramaturgia e, por fim, a formação de uma nova poética, com as características do contexto histórico-social (Buenaventura, apud Rizk, p. 16).

No ano de 1972, no Equador, foi realizado o Primeiro Festival de Teatro Latino- 
americano de Quito. Nesse encontro foi tomada a decisão fundamental de criação da Frente Latino-americana de Trabalhadores da Cultura. Reformulando os procedimentos de organização dos festivais anteriores, nesse encontro foi abolido o caráter competitivo e formado um coletivo de "jurados orientadores", composto por Augusto Boal, Atahualpa del Cioppo e Enrique Buenaventura.

Esse coletivo teve a função de fazer as críticas nos fóruns, reuniões e promover a organização de seminários. A criação da frente foi um avanço na articulação da produção teatral do continente. Em seu programa (Pianca, 1990, p. 349), é destacado a particularidade latino-americana e o papel da cultura nas lutas continentais. O documento inicia com uma leitura da conjuntura política na qual os grupos se posicionam contra a anexação norte-americana dos países latinos em uma integração econômica dependente, reafirma-se que necessitamos unificar todas as manifestações isoladas para transformar a cultura em um meio de libertação de nossos povos.

Depois de dois anos de espera, voltou a acontecer na Colômbia o consagrado encontro de Manizales, realizado em agosto de 1973. Em conjunto com esse V Festival, se organizou também a I Mostra Mundial. Nessa edição, aproximadamente 4000 pessoas presenciaram o Festival. Embora nesse encontro tenham sido dados novos passos importantes no processo de integração da produção teatral, com avanços na organização da Frente de Trabalhadores da Cultura, com o estabelecimento de novas ações e o desdobramento de mais dois encontros, um em Caracas e outro em Porto Rico, já se anunciavam os sinais do fim de um ciclo. Em 1973, poucos meses antes do Festival, se instaurou o golpe de estado no Uruguai e pouco após seu término se implantou a ditadura no Chile. Este Festival se realizou no contexto da mudança do tempo histórico. O grupo uruguaio El Galpón, de Atahualpa, não pôde participar do encontro em função do golpe. Perón também morreu no mesmo ano e a luta de classes na Argentina entrou em seu momento de intensa repressão. Do ponto de vista do Festival, para essa quinta edição, o caráter mundial implementado pelas autoridades locais visava minimizar e diluir a dimensão crítica e política do Festival.

É nessa conjuntura de disputas de projetos e impasses que Boal redige seu 
artigo "Revolução copernicana”, preparado ainda no início do ano para subsidiar o processo de escolha dos grupos representantes da Argentina e posteriormente divulgado na Colômbia durante o Festival. Torquemada, peça de Augusto Boal, é apresentada pelo grupo mexicano CLETA-UNAM. Essa peça de Boal, por sua temática, foi montada por diferentes grupos e apresentada em vários países do continente.

Nessa edição do festival na Colômbia foi realizado um novo encontro da Frente Latino-americana de Trabalhadores da Cultura e formulado um segundo comunicado com um chamado e os objetivos da Frente. Em assembleia reunida no encontro foi aprovada uma junta diretiva da Frente que funcionaria até o próximo encontro. Entre os eleitos pela assembleia, Augusto Boal aparece como o representante do Brasil.

Retomada: a Rede de Teatro e Vídeo Político Popular Nuestra América

O ciclo de ditaduras que afetou os países latino-americanos fortaleceu o aparato de dominação pela via dos meios ideológicos da Indústria Cultural, de forma articulada ao aparato repressivo direto. Essa dinâmica foi responsável pela garantia de condições para o ciclo neoliberal que assolou o continente.

Com a emergência de governos de esquerda e de centro-esquerda em reação ao desmonte neoliberal foram poucos os países que conferiram maior centralidade à questão da democratização dos meios de comunicação de massa, e à socialização dos meios de produção de bens simbólicos para a classe trabalhadora.

A articulação entre cultura, política e comunicação de modo geral permaneceu sendo residual na disputa política. Poucos movimentos sociais conferiram centralidade à questão, poucos governos decidiram enfrentar à questão, na medida em que essa decisão afetava a opção pela conciliação com as burguesias nacionais e com o capital transnacional - a exceção foi o governo venezuelano que tomou medidas efetivas contra o monopólio dos meios de 
comunicação e em prol da democratização da produção por meio de ações como a TeleSul, a TV Vive e o estímulo aos meios comunitários.

Agora, latino-americanos e, sobretudo, brasileiros vivem um momento de tensionamento máximo do pacto da democracia representativa, que chega ao limite para a classe dominante e para a classe trabalhadora e, na nova fase de luta a disputa pelas condições de diálogo e politização da classe trabalhadora passa diretamente pela socialização dos meios de produção simbólica e pela confrontação com o monopólio dos meios de comunicação de massa pela elite.

Além disso, como os governos de direita tendem a realinhar os elos entre si na América Latina e do subcontinente com os EUA é fundamental a expansão de uma ação articulada entre as forças de resistência em nossos países, o que passa pela formação pela perspectiva de uma visão geopolítica da América Latina e pelo intercambio das experiências acumuladas por nossas organizações.

Desde o ano de 2015, no segundo encontro da Rede Internacional Teatro e Sociedade, realizado na Universidade de Brasília (UnB), levantou-se a proposta de construção de um espaço de formação para militantes e artistas vinculados ao teatro de atuação crítica. Em 2016, em um encontro internacional de teatro político com grupos de oito países, realizado na ENFF, foi reforçada a necessidade de iniciar este processo e aprofundar o conhecimento das experiências já existentes no campo do teatro e vídeo popular e político.

Em dezembro de 2016, por convite da equipe da Escola de Teatro Político de Buenos Aires uma delegação brasileira, representantes de grupos argentinos de províncias do interior, e uma representante do Uruguai se reuniram para assistir as atividades de encerramento da segunda turma e para participar de um seminário com a intenção de planejar metodologia de uma possível escola latino-americana de teatro político. Entretanto, foi avaliado naquela ocasião, que antes de criar uma escola latino-americana era necessário que criássemos escolas semelhantes àquela em nossas cidades, estados e países. A partir desse encaminhamento as demais escolas passaram a ser construídas.

Entre 01 a 05 de novembro de 2017 foi realizado na Escola Nacional Florestan 
Fernandes, no Brasil, o primeiro encontro das coordenações da rede de escolas, e foi assumido como nome da ação coletiva de escola a Rede de Escolas de Teatro e Vídeo Político-Popular de Nuestra América. O objetivo geral do encontro foi dar continuidade aos processos anteriores, aprofundando os debates sobre os processos das escolas (metodologias, formas de organização, vínculos com os movimentos sociais), assim como aprofundar nosso debate e prática nos campos da pesquisa de linguagem e práxis artística. Na carta síntese os membros desse primeiro encontro da rede de escolas evocam seu compromisso com o legado de lutas anteriores e a disposição de manter a matriz da luta social como elemento estruturante da articulação:

A criação de nossas escolas de teatro e vídeo reafirma o compromisso de manter viva a memória das lutas contrahegemônicas e de fortalecer a identidade da classe trabalhadora e de suas articulações. O processo em curso têm vínculo histórico e se estrutura a partir de atos políticos e artísticos que reúnem esforços para o combate frente a ideologia burguesa, suas práticas políticas e imposição de modos de exploração cotidianamente defendidos e naturalizados pela indústria da cultura.

Diante da atual conjuntura da crise estrutural do capitalismo e dos golpes na América Latina, entendemos ser de grande importância pesquisar, criar e difundir procedimentos artísticos realizados por mulheres e homens da classe trabalhadora que se somem aos processos em curso de resistência anticapitalista.

As escolas de teatro e vídeo político-popular de nuestra américa continuarão o processo sobre o fazer e a produção artística e cultural em relação crítica com a sociedade, prestando contas sobre o real e apresentando o desejável com diversão, humor, consciência e atuação...em luta!

Atualmente existem quatro escolas da rede em funcionamento: a Escola de Teatro Popular do Rio de Janeiro, a Escola de Teatro Político e Vídeo Popular do Distrito Federal (Villas Bôas et all, 2019), a Escola de Teatro Político de Santa Catarina e a Escola Popular de Teatro e Vídeo de São Paulo (MST, 2019). E no segundo semestre de 2020 estão em processo de construção e abertura mais três escolas em estados brasileiros: a Escola de Teatro Político e Popular de Minas Gerais, a Escola de Teatro Político e Vídeo Popular do Piauí e a Escola Popular de 
Teatro de Alagoas.

Convergências e diferenças entre a Frente de Trabalhadores da Cultura e a Rede de Escolas Nuestra América

Se um dos traumas do ciclo de ditaduras latino-americanas seguido de largo período neoliberal foi a diluição da consciência política e cultural latino-americana dos grupos, decorrente da escassez dos espaços de encontro, intercâmbio e organização coletiva, é certo também que os coletivos que criaram a Frente de Trabalhadores da Cultura Nuestra America foram eficazes na sistematização de suas experiências, com a dramaturgia, os textos de intervenção, as entrevistas, a ponto de terem conseguido transmitir com eficácia o legado do modo de produção dos coletivos daquele período aos grupos contemporâneos.

Diogo Noventa, diretor da Cia Estudo de Cena, de São Paulo, expressa, em dezembro de 2016, em sua palestra, na mesa sobre Arte e Política - realizada na reunião da Rede Internacional Teatro e Sociedade, ocorrida na Escola de Teatro Político de Buenos Aires - diretrizes adotadas pela Estudo de Cena que já estavam presentes nas referências dos grupos do ciclo anterior:

Como desconstruir o ponto de vista dos que detém o poder dos meios de produção?

Jamais fazemos algum trabalho que tenha a impossibilidade de se comunicar com o público. Temos a preocupação também de não criar trabalhos que impossibilitem a conversa.

Nosso modo de trabalho é horizontal, não existe hierarquia de mando e econômica, embora existam funções para atingir melhor o objetivo em determinada criação. A sala de ensaio tem que ser muito livre, muito criativa. Sempre trabalhamos com a perspectiva de compartilhamento da imaginação entre todos envolvidos no processo tem que imaginar juntos, coletivizar a imaginação, não imaginar igual, mas imaginar juntos.

Nossa forma de teatro: não fazemos teatro de caixa, em espaços fechados. Estamos na rua, não por uma idealização da rua, mas por entender que precisamos estar em muitos outros locais em que nosso teatro possa dialogar com as pessoas sem querer depender das instituições culturais.

Consideramos que depender de outras instituições culturais diminui o potencial crítico. Portanto, caminhamos no sentido de sair das instituições, criar relações com outros grupos de teatro, com 
os movimentos sociais, temos relação com o MST. O local em que apresentamos comenta a peça e a peça comenta o local. O local não é apenas o palco, existe uma interação, e isso é fundamental para nós.

Estamos vivendo uma contribuição do teatro e da arte para que seja um momento de imaginar juntos, a imaginação coletiva pode ser uma possibilidade política nesses tempos de endurecimento, em que a burguesia não vem permitindo outras imaginações. Então, se o teatro consegue convocar as imaginações já é algo interessante e quando fazemos isso estamos criando uma nova cultura, estamos repensando o teatro. É o nosso fundamento e nossos processos internos. (2016, p. 05).

Se compararmos os contextos de origem das duas redes Nuestra América um dos pontos de semelhança é que ambas surgem como providência de resistência em contextos de ascensão de governos de extrema direita na América do Sul, como reação ao ciclo anterior de lutas populares e governos dispostos à realizar reformas estruturais em seus países, como a reforma agrária e a alfabetização da população.

A Frente de Trabalhadores da Cultura Nuestra América teve como elo central, como ponto de unidade, os festivais que agregavam os principais grupos de teatro político da América Latina. Em seus países os grupos promoviam processos de formação e multiplicação de suas experiências a partir da socialização dos meios de produção, e construíam suas pedagogias a partir da construção coletiva, em grande parte dos casos.

Todavia, a resistência e criatividade dos coletivos daquele período não foi capaz de se contrapor ao ciclo autoritário de regimes golpistas, que culminou com a eliminação da maior parte dos grupos, e com a erradicação da resistência das forças populares. No caso brasileiro, a experiência teatral dos anos 1960 foi interrompida pelo golpe de 1964 quando estava em processo de rápido amadurecimento. Há estudos que atestam que o processo de formação do teatro brasileiro, enquanto síntese dialética das influências externas e do processo de acumulação interna, ocorre naquela década, sobretudo, nos anos que antecedem o golpe militar-civil de 1964. (Costa, 1996; Villas Bôas, 2009).

O livro de Iná Camargo Costa, "A hora do teatro épico" (Graal, 1996) é a 
obra mais consistente sobre a questão. Nesse trabalho a autora alega que o processo brasileiro pulou do estágio inicial, de transferência dos meios de produção, para o estágio do massacre da experiência, tendo atropelado o segundo estágio, que é o da apropriação sistemática da classe trabalhadora dos meios de produção das linguagens artísticas.

É possível afirmarmos que há experiências, hoje em dia, nos coletivos de teatro político espalhados pelo país que não deixam nada a dever em termos de qualidade ao que de melhor foi produzido naquele período. Por outro lado, a associação orgânica daquela experiência a uma perspectiva de construção de um projeto de país é algo que não reapareceu nas décadas seguintes ao golpe de 1964.

No período contemporâneo a Rede de Escolas de Teatro e Vídeo PolíticoPopular de Nuestra América tem como principal eixo de trabalho a consolidação de escolas de formação política e estética, com principal ênfase no trabalho com as linguagens de teatro e vídeo popular. As coordenações das escolas são formadas por militantes de movimentos sociais do campo e da cidade, dos coletivos de teatro e vídeo que atuam junto a esses movimentos nos estados, e em alguns casos por representantes de organizações sindicais.

Enquanto no período anterior o desafio era combater as ditaduras que se instauraram no continente, aliadas das políticas imperialistas estadunidenses, e restaurar a democracia nos países latino-americanos, no momento atual o embate se dá contra o neofascismo que avança por dentro de democracias liberais, destruindo estruturas democráticas que foram construídas no decorrer de décadas. No caso brasileiro, desde o impeachment da presidenta Dilma Roussef a cultura e a arte sofrem perseguições nas redes sociais, atos de vandalismo, censura de gestores de aparelhos culturais, cortes orçamentários, assistem ao fim de programas de investimento em fomento, produção, formação e circulação e até mesmo ao fim do Ministério da Cultura.

No Brasil do governo Bolsonaro a articulação em rede das escolas significa, até o momento, um gesto pequeno de resistência diante do avanço destrutivo das políticas neoliberais e da repressão violenta ao pensamento crítico e a arte 
comprometida com as demandas e anseios da classe trabalhadora. Entretanto, do ponto de vista simbólico, as escolas significam um passo importante para a retomada da articulação da produção do teatro popular latino-americano, na medida em que integram movimentos sociais do campo e da cidade, construindo redes de produção e circulação de teatro e vídeo vinculadas com processos de formação política e estética em territórios periféricos completamente desassistidos de aparelhos culturais. De tal forma que novos circuitos que integram casas de cultura da periferia, espaços de formação de movimentos e sindicatos, escolas públicas e campi de universidades, acampamentos rurais e urbanos de luta pela reforma agrária ou moradia e trabalho vão se integrando, fortalecendo a organização social das comunidades nos territórios.

O papel do teatro nesses processos desempenha múltiplas funções. E podemos notar fortes semelhanças com a dinâmica sistematizada por Eugenia Cassini Ropa (2014), no texto "A arma do teatro", sobre o teatro político das décadas de 1920 e 1930: como linguagem artística, o teatro fornece imagens não mercantilizadas de um mundo cujas contradições podem, e devem, ser superadas pela ação da humanidade, tendo em vista a perspectiva emancipatória; como instrumento de agitação e propaganda, o teatro é potencializado por meio de brigadas, no campo e na cidade, e nas escolas, pelo papel de educadores críticos, cientes do sentido humanizador que a arte pode cumprir quando associada à dimensão da formação e educação; como forma de disputa com os instrumentos de persuasão e manipulação da Indústria Cultural, o teatro pode colocar em campo seus procedimentos estéticos à serviço da crítica contra o fetichismo da mercadoria, em chave desideologizadora.

\section{Referências}

BOAL, Augusto. Técnicas Latinoamericanas de Teatro Popular (Uma revolución Copernicana al revés). Buenos Aires: Ediciones Corregidor, 1975.

BOAL, Augusto. Teatro do Oprimido e outras poéticas políticas. São Paulo: Cosac Naify, 2013. 
BOAL, Augusto. Técnicas latinoamericanas de teatro popular: una revolución copernicana al revés. 2 ed. Buenos Aires: Corregidor, 2014.

CARDOSO, Fernando Henrique; FALETTO, Enzo. Dependência e desenvolvimento na América Latina: ensaio de interpretação sociológica. 6 edição. Rio de Janeiro: Zahar Editores, 1981.

COSTA, Iná Camargo. A hora do teatro épico no Brasil. Rio de Janeiro: Graal, 1996.

Documento sobre o teatro popular, 1968, Manizales. In: PIANCA, Marina. El Teatro de Nuestra America: un proyecto continental, 1959-1989. Minneapolis: Institute for the Study of Ideologies and Literature, 1990, p. 335-340.

ESTEVAM; Douglas. Augusto Boal and the Nuestra America theatre. In: HOWE; Kelly; BOAL; Julian; SOEIRO; José (orgs). The Routledge companion to Theatre of the Oppressed. Abingdon, Oxon; New York: Routledge, 2019.

GARCIA, Santiago. Teoria e prática do teatro. São Paulo: Hucitec, 1988.

Relatório da delegação brasileira na reunião da Rede Internacional Teatro e Sociedade ocorrida em Buenos Aires. Dezembro de 2016.

GUTIÉRREZ, Sônia. Teatro Popular y cambio social en America Latina: panorama de una experiencia. Costa Rica: Editorial Universitaria Centroamericana, 1979.

LEAL, Rino. Teatro Escambray. La Habana: Editorial Letras Cubanas, 1978.

LIMA, Eduardo Campos. Coisas de Jornal no Teatro. São Paulo: Expressão Popular, 2014.

MARINI, Ruy Mauro. “Dialética da dependência”. In: SADER, Emir. Dialética da Dependência. Petrópolis: Vozes, 2000.

MST, Coletivo de Comunicação do. MST realiza Escola Popular de Teatro e Vídeo de São Paulo. Link: http://www.mst.org.br/2019/07/25/mst-realiza-escolapopular-de-teatro-e-video-de-sao-paulo.html. Acesso em: 30 jul. 2019.

PIANCA, Marina. El Teatro de Nuestra America: un proyecto continental, 19591989. Minneapolis: Institute for the Study of Ideologies and Literature, 1990.

RIZK, Beatriz J. El Nuevo Teatro Latinoamericano: uma lectura histórica. Minneapolis: Prisma Institute, 1987.

ROPA, Eugenia Casini. A dança e o agit-prop: os teatros não teatrais na cultura alemã do início do século XX. São Paulo: Perspectiva, 2014.

VILLAS BÔAS, Rafael Litvin. Teatro político e questão agrária, 1955-1965: 
contradições, avanços e impasses de um momento decisivo. Brasília, 2009. Tese (Doutorado) - Programa de Pós-Graduação em Literaturas, Universidade de Brasília.

VILLAS BÔAS, Rafael Litvin. Invisible Theatre: from origins to current uses. In: HOWE; Kelly; BOAL; Julian; SOEIRO; José (orgs). The Routledge companion to Theatre of the Oppressed. Abingdon, Oxon; New York: Routledge, 2019.

VILLAS BÔAS, Rafael Litvin; PINTO, Viviane Cristina; ROSA, Simone Menezes. A Escola de Teatro Político e Vídeo Popular do Distrito Federal: formação pela práxis. In: Urdimento, Florianópolis, v.1, no 34, p. 36-47, 2019. Disponível no link: http://www.revistas.udesc.br/index.php/urdimento/article/view/1414573101342019 $\underline{036 / 9956}$

Recebido em: 30/06/2020

Aprovado em: 28/08/2020 